\title{
The antineoplastic drug, trastuzumab, dysregulates metabolism in iPSC-derived cardiomyocytes
}

\author{
Brian M. Necela' ${ }^{1}$, Bianca C. Axenfeld ${ }^{1}$, Daniel J. Serie ${ }^{2}$, Jennifer M. Kachergus ${ }^{1}$, Edith A. Perez ${ }^{3}$, \\ E. Aubrey Thompson ${ }^{1}$ and Nadine Norton ${ }^{1^{*}}$ (D)
}

\begin{abstract}
Background: The targeted ERBB2 therapy, trastuzumab, has had a tremendous impact on management of patients with HER2+ breast cancer, leading to development and increased use of further HER2 targeted therapies. The major clinical side effect is cardiotoxicity but the mechanism is largely unknown. On the basis that gene expression is known to be altered in multiple models of heart failure, we examined differential gene expression of iPSC-derived cardiomyocytes treated at day 11 with the ERBB2 targeted monoclonal antibody, trastuzumab for $48 \mathrm{~h}$ and the small molecule tyrosine kinase inhibitor of EGFR and ERBB2.

Results: Transcriptome sequencing was performed on four replicates from each group ( $48 \mathrm{~h}$ untreated, $48 \mathrm{~h}$ trastuzumab and $48 \mathrm{~h}$ lapatinib) and differential gene expression analyses were performed on each treatment group relative to untreated cardiomyocytes. 517 and 1358 genes were differentially expressed, $p<0.05$, respectively in cardiomyocytes treated with trastuzumab and lapatinib. Gene ontology analyses revealed in cardiomyocytes treated with trastuzumab, significant down-regulation of genes involved in small molecule metabolism $\left(p=3.22 \times 10^{-9}\right)$ and cholesterol $(p=0.01)$ and sterol $(p=0.03)$ processing. We next measured glucose uptake and lactate production in IPSC-derived cardiomyocytes 13 days post-plating, treated with trastuzumab up to $96 \mathrm{~h}$. We observed significantly decreased glucose uptake from the media of iPSC-derived cardiomyocytes treated with trastuzumab as early as $24 \mathrm{~h}$ ( $p=0.001)$ and consistently up to $96 \mathrm{~h}(\mathrm{p}=0.03)$.
\end{abstract}

Conclusions: Our study suggests dysregulation of cardiac gene expression and metabolism as key elements of ERBB2 signaling that could potentially be early biomarkers of cardiotoxicity.

\section{Background}

As major advances are being made to understand the biology of the disease and optimize therapeutic benefit of various treatment strategies, side effects associated with those treatments must also be understood in order to minimize the dose/treatment limiting effects of such complications. One of the most impactful therapies for breast cancer is the humanized monoclonal antibody, trastuzumab (Herceptin ${ }^{\circledR}$ ), which specifically recognizes the HER2 protein encoded by the ERBB2 gene. HER2 is

\footnotetext{
*Correspondence: Norton.nadine@mayo.edu

1 Department of Cancer Biology, Mayo Clinic, Jacksonville, FL, USA Full list of author information is available at the end of the article
}

part of a family of transmembrane receptors, is overexpressed in about $15-20 \%$ of invasive breast cancers, and is associated with aggressive biology and a natural history of shortened survival.

The original pivotal trial of trastuzumab in patients with HER2-positive metastatic breast cancer created concern for the cardiac safety of patients receiving HER2 inhibitors after $27 \%$ of patients treated with concurrent anthracycline (when given at a cumulative dose of $\left.>300 \mathrm{mg} / \mathrm{m}^{2}\right) /$ cyclophosphamide/trastuzumab and $13 \%$ of those treated with trastuzumab/paclitaxel experienced some degree of cardiotoxicity [1]. Data from multiple randomized adjuvant trials and observational studies suggest that the rate of discontinuation of trastuzumab 
treatment ranges between 6 and 31\%, mainly due to cardiotoxicity [2-10]; and in patients aged $\geq 65$ years old, this figure increases to a notable and clinically relevant rate of $41 \%$ [11].

Trastuzumab is a monoclonal antibody that targets the protein HER2, but the mechanisms that account for trastuzumab-mediated cardiotoxicity are largely unknown. The expert consensus statement from the American Society of Echocardiography and the European Association of Cardiovascular imaging, classifies Trastuzumab as a Type II Cancer therapeutics-related cardiac dysfunction (CTRCD) agent because it does not directly cause cell damage in a cumulative dose-dependent fashion (unlike Type 1 CTCRD/anthracycline cardiotoxicity), and observed cardiac dysfunction is often reversible when treatment is discontinued $[12,13]$. However classification of cardiotoxicity as Type I or II is confounded by the fact that such treatments are often given sequentially or concurrently and that echocardiography may miss subtle cardiac defects which do not change left ventricular ejection fraction (LVEF) measurement.

To some extent, these factors have been addressed in animal models, which allow single treatment with trastuzumab and more invasive testing methods. ErbB2deficient conditional mutant adult mice were viable and displayed no overt phenotype, but physiological analysis revealed a phenotype consistent with dilated cardiomyopathy $[14,15]$. Isolated cardiomyocytes from conditional mutants were more susceptible to anthracycline toxicity, demonstrating that ErbB2 signaling in cardiomyocytes is requisite for the prevention of dilated cardiomyopathy (DCM) [14].

More recent pharmacological studies in both mouse and zebrafish suggest that the link between ErbB2 inhibition and DCM is not directly linked to cardiomyocyte survival; rather that pharmacological inhibition of ErbB2/ erbb2 (without combination treatment with anthracycline), can result in myofibril remodeling. Treatment of wild type mice with trastuzumab, resulted in impaired ventricular function, ultrastructural damage of heart tissue (stretched appearance and reduced thickness of ventricular cardiac myofibers), and differential expression of 15 genes involved in adaptability to cardiac contractility, hemodynamic stress, DNA repair mechanisms, apoptosis, and mitochondrial function [16]. Taken together, mouse and zebrafish studies suggest that ErbB2/erbb2 inhibition plays a role in cardiomyocyte survival following anthracycline treatment, but also directly affects the structural organization of specific subpopulations of ventricular myofibrils, even in the absence of anthracycline.

The limitations of these studies is their reliance on genetic models of erbb2 inhibition, or in the case of pharmacological experimentation, trastuzumab is a humanized monoclonal antibody and may not have the same efficacy in the mouse. Trastuzumab is not an option in zebrafish models, and the pharmacological inhibition in the literature [17-19] used PD168393, a compound that inhibits both EGFR and ERBB2 but is not used in the clinic.

Human induced pluripotent stem cell (hiPSC) derived cardiomyocytes are now a convenient option for the assessment cardiotoxicity of clinically relevant drugs in humans. On the basis that trastuzumab has been shown to alter the expression of genes essential for cardiac contractility in a mouse model [16] and that different gene expression profiles in multiple models of heart failure are well known [20-25], we hypothesized that detailed examination of trastuzumab induced differential gene expression in human iPSC-derived cardiomyocytes could provide insight into the genes, pathways and potential biomarkers of trastuzumab induced cardiotoxicity.

\section{Methods \\ Compounds}

Trastuzumab, was received from Genentech (South San Francisco, CA) as a gift. Lapatinib Ditosylate was purchased from LC Laboratories (Woburn, MA). We used $100 \mu \mathrm{g} / \mathrm{mL}$ trastuzumab to represent a clinically relevant dose. In studies of patients in which an initial dose of $4 \mathrm{mg} / \mathrm{kg}$ was followed by a weekly maintenance dose of $2 \mathrm{mg} / \mathrm{kg}$, in combination with chemotherapy, the mean \pm S.D. peak serum trastuzumab concentration at week 8 was $101.0 \pm 30.6 \mu \mathrm{g} / \mathrm{mL}(\mathrm{n}=115)$. Among patients receiving trastuzumab alone, mean \pm S.D. peak concentration at week 8 was $95.6 \pm 35.9 \mu \mathrm{g} / \mathrm{mL}$ [26]. We used $2 \mu \mathrm{M}$ lapatinib Ditosylate based on previous observations [27].

\section{Breast cancer cell culture}

SKBR3, BT474, HCC1954, MDA-MB-453, HCC1569, and HCC1419 breast cancer cell lines were purchased from ATCC (Manassas, VA). SKBR3 and BT474 cell lines were maintained at in IMEM supplemented with $10 \%$ fetal bovine serum (FBS) and cultured at $37{ }^{\circ} \mathrm{C}, 5 \% \mathrm{CO}_{2}$. HCC1954, HCC1569, and HCC1419 cells were cultured in RPMI with $10 \% \mathrm{FBS}$ at $37{ }^{\circ} \mathrm{C}, 5 \% \mathrm{CO}_{2}$. MDA-MB-453 cells were cultured in L-15 with $10 \%$ FBS at $37{ }^{\circ} \mathrm{C}$, no $\mathrm{CO}_{2}$. All cells passaged with $0.25 \%$ trypsin as needed.

\section{Cardiomyocyte cell culture}

iCell $^{\circledR}$ cardiomyocytes were purchased from CELLular Dynamics International, CDI (Madison, WI) maintained according to the manufacturer's recommended instructions. Cardiomyocytes were seeded with CDI's plating media into fibronectin $(5 \mu \mathrm{g} / \mathrm{mL})$ coated wells at the appropriate density $\left(2.4^{\mathrm{e} 5}\right.$ cells per well of 12 well plate; 
$2^{\mathrm{e} 4}$ per well of 96 well plate. After 2 days, media was changed to CDI's maintenance media and replaced every other day. Cells were maintained at $37{ }^{\circ} \mathrm{C}, 7 \% \mathrm{CO}_{2}$ until 10 days after plating at which time cells were treated with the appropriate drug for $48 \mathrm{~h}$ and endpoint assays (RNA extraction, viability/apoptosis) performed.

\section{Western blot analysis}

$15 \mu \mathrm{g}$ total cell lysates were prepared by briefly sonicating cell pellets in $1 \times$ lysis buffer (Cell Signaling) supplemented with a protease inhibitor mixture (Roche) and phosphatase inhibitors (PhosSTOP, Roche). Protein samples were resolved on Bolt $8 \%$ Bis-Tris Plus gels (ThermoFisher) and were electrophoretically transferred to a polyvinylidene difluoride membrane and blocked for $1 \mathrm{~h}$ at room temperature with $5 \%$ dry milk in TBST $(50 \mathrm{mM}$ Tris, $150 \mathrm{mM} \mathrm{NaCl}, 0.1 \%$ Tween, $\mathrm{pH}$ 7.5). Blots were stained with antibodies against EGFR (D38B1), HER2/ERRB2 (D8F12), HER3/ERRB3(D22C5), and HER4/ERBB4 (111B2), and GAPDH (D16H11) purchased from Cell Signaling Technology and used a dilution of $1: 1000$ in $5 \%$ dry milk in TBST for $1 \mathrm{~h}$ at $22^{\circ} \mathrm{C}$. For detection of PHLDA1 expression, blots were stained with 1;1000 dilution of anti-PHLDA1 antibody (EPR6674, abcam $^{\circledR}$ ). For detection of PDK4 expression, blots were stained with $2 \mu \mathrm{g} / \mathrm{mL}$ dilution of anti-PDK4 (NBP107049, Novus Biologicals). All blots were washed with three changes of TBST for a total of $45 \mathrm{~min}$. Blots were then incubated in TBST buffer with 5\% dry milk containing GAR-HRP (1:10,000, Cell Signaling Technology) for $1 \mathrm{~h}$ at room temperature. After three washes with TBST, antigen-antibody complexes were detected with the ECL Plus chemiluminescent system (Amersham Biosciences) and visualized with film.

\section{Transcriptome sequencing}

RNA was extracted from breast cancer cell lines and iPSC-derived cardiomyocytes with the RNeasy minikit (Qiagen). RNASeq libraries were prepared with the TruSeq v2 (Illumina Inc, San Diego, Ca), and sequenced by 101 base paired-end sequencing on an Illumina HiSeq 2000 (Illumina Inc, San Diego, Ca), mRNA as per the manufacturer's instructions. Quality control, sequence alignment and gene expression counts were obtained using MAP-R seq workflow [28]. Transcriptome data is deposited in GEO, accession number GSE91383.

\section{Quantitative PCR}

Two-step quantitative reverse transcriptase-mediated real-time PCR (qPCR) was used to measure abundance of individual mRNAs. Equal aliquots of total RNA from samples were converted to cDNA with the HighCapacity cDNA Archive kit (Applied Biosystems), and
qPCR reactions were performed in triplicate with $10 \mathrm{ng}$ of cDNA and the TaqMan Universal PCR master mix (Applied Biosystems). Primer/probe sets were purchased from Applied Biosystems. Amplification data were collected with an Applied Biosystems ViiA7 detector and analyzed with ViiA7 v 1.2.4 software (Life Technologies). Data were normalized to the endogenous control POLR2A [29] and mRNA abundance was calculated using the $\Delta \triangle \mathrm{CT}$ method [30].

\section{Metabolic assays}

Glucose was measured in cell culture supernatant by Amplex ${ }^{\circledR}$ Red Glucose/Glucose Oxidase Assay (ThermoFisher). Fluorescence was measured at 530/590 nm, and glucose concentration calculated via standard curve. Lactate was measured in cell culture supernatant using the Lactate Colorimetric/Fluorometric Kit (Biovision). Fluorescence was measured at 535/587 nm.

\section{Apoptosis assay}

Apoptosis was measured by caspase- $3 / 7$ activation with the ApoTox-Glo assay (Promega) as per the manufacturer's instructions.

\section{Statistical analyses}

RNASeq statistical analyses were conducted with $R$ version 3.1.1. Transcriptome-wide differential expression analyses were undertaken via the edgeR package, version 3.8.6. Cell lines and cardiomyocytes treated with trastuzumab or lapatinib were compared to untreated samples (four replicates each group). Genes with less than two samples expressed at two counts-per-million or greater were considered beneath the threshold of detection and filtered from all analyses. To correct for multiple testing, Benjamini and Hochberg's FDR method was applied and a threshold of $\mathrm{q}<0.05$ was considered significant.

Gene enrichment analyses were performed with the Gene Ontology (GO) Consortium database [31, 32] in each cell type following ERBB2 inhibition. For each transcriptome, we took those genes differentially expressed, $\mathrm{p}<0.05$ and searched for enrichment of gene ontology categories by biological process.

Significance of qPCR fold change, glucose uptake, lactate production and apoptosis following treatment with trastuzumab or lapatinib was analyzed by $T$ test in Graphpad Prism.

\section{Results}

ERBB expression in iPSC-derived cardiomyocytes and cancer cell lines overexpressing ERBB2

To put into context, ERBB2 expression levels in cancer cell lines overexpressing ERBB2 and iPSC-derived cardiomyocytes, we examined RNA and protein expression levels of 
the ERBB family. Gene expression of all members of the ERBB family of tyrosine kinase receptors was detected in cardiomyocytes and cancer cell lines overexpressing ERBB2 (Fig. 1). As expected, ERBB2 expression was significantly higher in the ERBB2-overexpressing cancer cell lines (mean $12.9 \log 2$ counts per million), but ERBB2 was also expressed in iPSC-derived cardiomyocytes, $8.96 \log 2$ counts per million. ERBB2 gene expression is shown separately for each of the six cancer cell lines in Fig. 1.

Protein levels of each ERBB family member in iPSCderived cardiomyocytes are shown in Fig. 2. Using $15 \mu \mathrm{g}$ of cell lysate, only ERBB2 and ERBB4 were detected at the protein level in iPSC-derived cardiomyocytes. The lack of EGFR expression in the iPSC-derived cardiomyocytes suggests that the action of lapatinib which targets EGFR and ERBB2 is not through inhibition of EGFR,

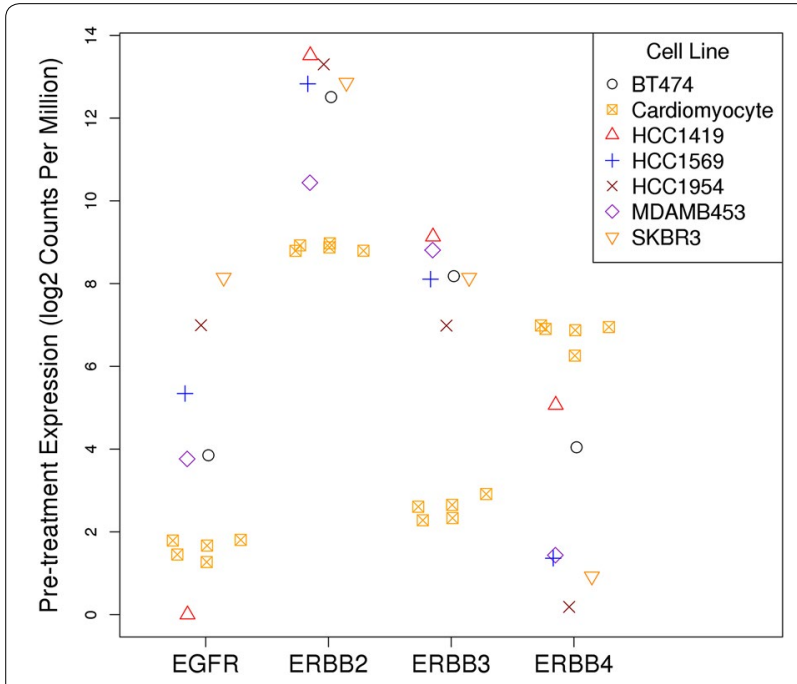

Fig. 1 RNA expression of ERBB family in iPSC-derived cardiomyocytes and cancer cell lines overexpressing ERBB2. At the level of RNA, ERBB2-overexpressing cancer cell lines express higher levels of ERBB2 by $\sim 1-5$ orders of magnitude relative to iPSC-derived cardiomyocytes. IPSC-derived cardiomyocytes expressed moderate levels of ERBB4, and low levels of EGFR and ERBB3

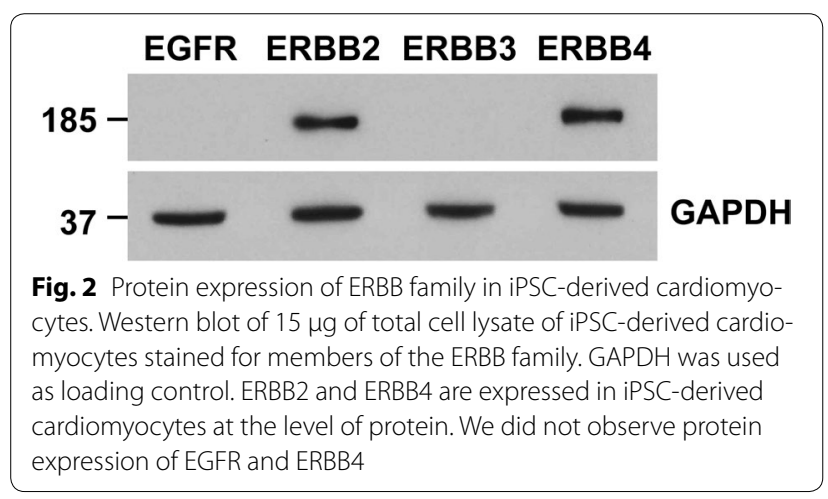

but either ERBB2 or ERBB2 in combination with any off-target effects. ERBB2 protein was down-regulated by trastuzumab in iPSC-derived cardiomyocytes, but not by lapatinib. Trastuzumab did not down-regulate ERBB2 protein expression in ERBB2 overexpressing cancer cell lines (Fig. 3).

\section{Trastuzumab induced significant differential gene expression in iPSC-derived cardiomyocytes}

517 genes were differentially expressed in iPSC-derived cardiomyocytes treated with trastuzumab at $\mathrm{p}<0.05$, of which 137 showed fold change $>1.5$ (49 down-regulated, 88 up-regulated). Only one gene, IL31RA remained significant following correction for multiple testing, fold change $3.85, \mathrm{p}=1.56 \times 10^{-6}, \mathrm{q}=0.025$. Full differential expression results are shown in Additional file 1: Table S1.

Overlap of trastuzumab induced differentially expressed genes is relatively small between ERBB2-overexpressing cancer cell lines and iPSC-derived cardiomyocytes We observed a high degree of overlap in the genes expressed in iPSC-derived cardiomyocytes and

a

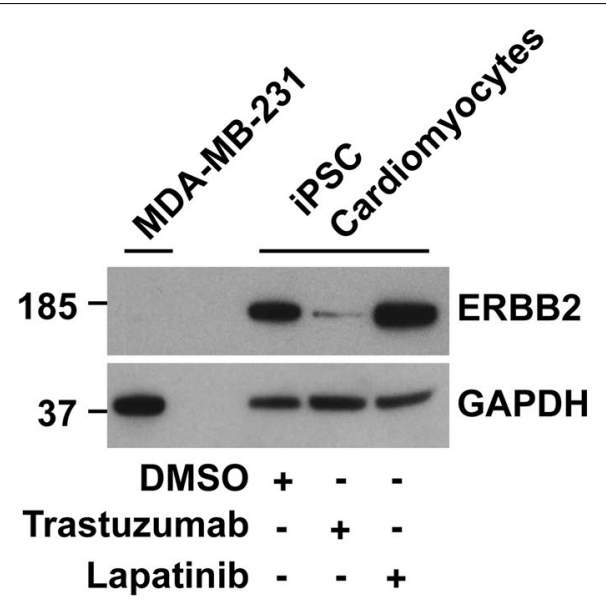

b

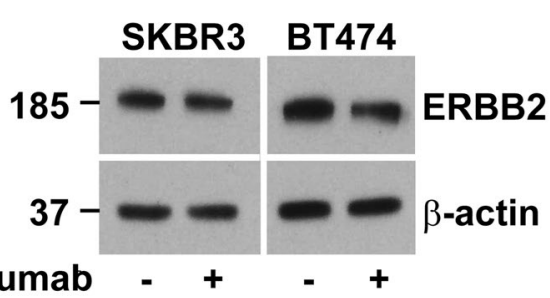

Fig. 3 Trastuzumab down-regulates ERBB2 in iPSC-derived cardiomyocytes, but not in ERBB2 overexpressing cancer cell lines. a Western blot of $15 \mu \mathrm{g}$ of total cell lysate stained for ERBB2 in MDA-MB-231 (non-ERBB2 overexpressing breast cancer cell line negative control), and iPSC-cardiomyocytes treated with trastuzumab and lapatinib. ERBB2 expression was down-regulated by trastuzumab but not by lapatinib. b ERBB2 expression was not altered by trastuzumab in the ERBB2 overexpressing cancer cell lines, BT474 and SKBR3 
ERBB2-overexpressing cancer cell lines. Of the 14,946 genes expressed above background in the cancer cell lines, 11,466 (77\%) were also expressed above background in the iPSC cardiomyocytes (Additional file 2: Figure S1A). As further validation of changes in gene expression mediated by ERBB2 inhibition, we next assessed the overlap of trastuzumab induced differential gene expression between the ERBB2-overexpressing cancer cell lines and iPSC-derived cardiomyocytes. $76 / 11,466(0.66 \%)$ genes expressed in both cell types were differentially expressed, $\mathrm{p}<0.05$, (Additional file 2: Figure S1B). 76 genes were differentially expressed, $p<0.05$ in both cancer cell lines and iPSC-derived cardiomyocytes following treatment with trastuzumab (Table 1). 63/76 genes showed fold changes in the same direction in both cancer cell lines and iPSC-derived cardiomyocytes.

Validation of trastuzumab induced differentially expressed genes in iPSC-derived cardiomyocytes by additional ERBB2 targeted compounds

We also performed transcriptome sequencing on iPSCderived cardiomyocytes following $48 \mathrm{~h}$ treatment with the small molecule tyrosine kinase inhibitor, lapatinib, and examined differential gene expression of treated versus untreated cells. We observed a total of 1358 genes that were differentially expressed following treatment with lapatinib at $\mathrm{p}<0.05$, of which 533 showed fold change $>1.5$ (271 up-regulated and 262 down-regulated). 75 genes remained significant $\mathrm{q}<0.05$ after correction for multiple testing, the most significant of which was PHLDA1, $\mathrm{p}=8.89 \times 10^{-9}, \mathrm{q}=0.0001$, fold change 0.29 . Differential gene expression data for all genes following treatment with lapatinib is shown in Additional file 3: Table S2.

$38 / 137$ (28\%) of genes that were differentially expressed in iPSC cardiomyocytes following treatment with trastuzumab, were also differentially expressed following treatment with lapatinib, $\mathrm{p}<0.05$ and fold change $>1.5$, (Table 2), including the most significantly differentially expressed genes from both drugs, IL31RA from trastuzumab and PHLDA1 from lapatinib. $93 \%$ of genes that were differentially expressed following treatment with lapatinib were not significantly changed by treatment with trastuzumab, demonstrating the wider range of effect of the tyrosine kinase inhibitor relative to monoclonal antibody.

To validate the differentially expressed genes identified by transcriptome sequencing, we selected genes with fold changes $>1.5, \mathrm{p}<0.05$, following treatment with both trastuzumab and lapatinib: EGR1, PHLDA1, RGS4, SLC6A6 for qPCR in RNA extracted from two separate batches of iPSC-derived cardiomyocytes (Fig. 4). To further evaluate ERBB2 inhibition of these genes, we also treated cells from a new batch of iPSC-derived cardiomyocytes with additional ERBB2 inhibitors, neratinib, afatinib and poziotinib. PHLDA1 and SLC6A6 were significantly down-regulated by all inhibitors (Additional file 4: Figure S2). We also confirmed down-regulation of PHLDA1 at the level of protein expression by Western blot, (Fig. 5).

\section{ERBB2 inhibition down-regulates genes involved in metabolism in iPSC-derived cardiomyocytes and ERBB2-overexpressing cancer cell lines}

We used gene ontology (GO) [31, 32] to perform gene enrichment analyses in each cell type following ERBB2 inhibition. For each transcriptome, we took those genes differentially expressed at $\mathrm{p}<0.05$ and searched for enrichment of gene ontology categories by biological process. Following Bonferroni correction of each GO term, a total of $272 \mathrm{GO}$ terms were associated at $\mathrm{p}<0.05$ with differentially expressed genes in ERBB2-overexpressing cancer cell lines treated with trastuzumab. Not surprisingly, the majority of these terms related to cell cycle processes, with mitotic cell cycle, GO:0000278 being the most significant, $\mathrm{p}=2.62 \times 10^{-42}$ (Additional file 5: Table S3). We observed a similar trend in cardiomyocytes treated with lapatinib. $88 \mathrm{GO}$ terms were associated at $\mathrm{p}<0.05$ with differentially expressed genes, the most significant terms being, mitotic nuclear division, GO:0007067, $\mathrm{p}=1.09 \times 10^{-15}$ and mitotic cell cycle process, GO:1903047, $\mathrm{p}=1.68 \times 10^{-14}$ (Additional file 6: Table S4).

However, in cardiomyocytes treated with trastuzumab, following Bonferroni correction, only $20 \mathrm{GO}$ terms were associated at $\mathrm{p}<0.05$ with the differentially expressed genes, all of which related to metabolism. The most significant GO term was small molecule metabolic process, $\mathrm{p}=3.22 \times 10^{-9}$ (which included the taurine transporter, SLC6A6, already shown to be significantly down-regulated by multiple ERBB2 inhibitors in $\mathrm{qPCR}$ validation) and multiple terms relating to cholesterol processing were associated [cholesterol biosynthetic process (GO:0006695), cholesterol metabolic process (GO:0008203) and sterol biosynthetic process (GO:0016126) (Additional file 7: Table S5)]. Post-hoc examination of the differentially expressed genes within these categories identified the same set of recurring genes (LDLR, SREBF1, ABCA1, CLN6, MSMO1, INSIG1, NSDHL, DHCR24, DHCR7, IDI2, FDPS, IDI1) detailed in Additional file 8: Table S6, 11/12 of which were downregulated by trastuzumab.

The same GO terms relating to small molecule metabolic process and cholesterol metabolic process in cardiomyocytes treated with trastuzumab, were also significant in cardiomyocytes treated with lapatinib (GO:0044281, 
Table 176 genes were differentially expressed in both ERBB2-overexpressing cancer cell lines and iPSC-derived cardiomyocytes, following treatment with trastuzumab, $p<0.05$

\begin{tabular}{|c|c|c|c|c|c|c|}
\hline \multirow[t]{2}{*}{ Gene } & \multicolumn{3}{|c|}{ ERBB2-overexpressing cancer cell lines } & \multicolumn{3}{|c|}{ iPSC-derived cardiomyocytes } \\
\hline & $\log C P M$ & FC & p value & $\log C P M$ & $\mathrm{FC}$ & p value \\
\hline DDX60 & 4.37 & 1.31 & $2.32 \mathrm{E}-04$ & 4.42 & 1.68 & 0.001 \\
\hline GABRP & 3.10 & 1.43 & 0.032 & 0.51 & 2.46 & 0.001 \\
\hline DHCR24 & 9.72 & 0.82 & 0.001 & 5.84 & 0.68 & 0.002 \\
\hline DHCR7 & 7.60 & 0.75 & $1.06 \mathrm{E}-04$ & 4.53 & 0.70 & 0.002 \\
\hline$B M F$ & 5.23 & 1.49 & $1.49 E-04$ & 6.86 & 1.48 & 0.002 \\
\hline PTPRE & 2.23 & 1.27 & 0.036 & 3.21 & 1.71 & 0.002 \\
\hline INSIGI & 6.79 & 0.72 & $9.13 \mathrm{E}-05$ & 4.21 & 0.72 & 0.003 \\
\hline TYMS & 5.54 & 0.81 & 0.030 & 6.02 & 0.67 & 0.003 \\
\hline$S C D$ & 10.80 & 0.59 & 0.000 & 6.18 & 0.69 & 0.004 \\
\hline ZNF9O & 1.88 & 0.66 & 0.039 & 2.21 & 0.70 & 0.006 \\
\hline SEMAGC & 3.01 & 1.80 & 0.001 & 6.18 & 1.36 & 0.006 \\
\hline PRSS23 & 6.64 & 1.22 & $6.12 \mathrm{E}-04$ & 4.95 & 1.38 & 0.006 \\
\hline CDK1 & 7.12 & 0.80 & 0.023 & 5.25 & 0.70 & 0.007 \\
\hline REPS2 & 4.96 & 1.15 & 0.021 & 4.96 & 1.46 & 0.007 \\
\hline$L D L R$ & 7.78 & 0.81 & $1.63 \mathrm{E}-04$ & 5.84 & 0.66 & 0.007 \\
\hline YARS & 7.38 & 0.89 & 0.027 & 6.97 & 0.79 & 0.007 \\
\hline MSMO1 & 6.95 & 0.80 & 0.002 & 5.51 & 0.72 & 0.008 \\
\hline UBE2T & 5.57 & 0.87 & 0.023 & 4.74 & 0.71 & 0.012 \\
\hline SEPP1 & 5.87 & 1.32 & 0.006 & 5.56 & 1.29 & 0.015 \\
\hline SREBF1 & 9.23 & 0.85 & 0.008 & 4.06 & 0.69 & 0.015 \\
\hline$C L U$ & 8.72 & 1.23 & $9.44 \mathrm{E}-04$ & 5.81 & 1.37 & 0.016 \\
\hline TOMM40 & 6.91 & 0.84 & 0.002 & 5.37 & 0.74 & 0.017 \\
\hline$A B C A 1$ & 2.46 & 1.43 & 0.003 & 5.32 & 1.48 & 0.017 \\
\hline NSDHL & 5.41 & 0.84 & 0.004 & 4.22 & 0.77 & 0.018 \\
\hline KIF18B & 5.33 & 0.78 & 0.014 & 3.52 & 0.70 & 0.018 \\
\hline ERO1LB & 4.05 & 1.21 & 0.025 & 3.76 & 1.35 & 0.019 \\
\hline NEIL3 & 4.17 & 0.80 & 0.036 & 1.84 & 0.66 & 0.019 \\
\hline HIST2H2BE & 5.09 & 1.20 & 0.019 & 6.96 & 1.34 & 0.019 \\
\hline TUBA1B & 7.79 & 0.81 & 0.015 & 7.92 & 0.75 & 0.021 \\
\hline FDPS & 7.37 & 0.80 & 0.001 & 5.83 & 0.82 & 0.022 \\
\hline ERV3-1 & 3.53 & 1.18 & 0.027 & 3.95 & 1.38 & 0.023 \\
\hline ACAT2 & 5.76 & 0.72 & 0.002 & 4.80 & 0.74 & 0.024 \\
\hline$P P L$ & 6.33 & 1.11 & 0.048 & 4.97 & 1.38 & 0.024 \\
\hline NBR1 & 7.15 & 1.12 & 0.026 & 7.24 & 1.25 & 0.027 \\
\hline PDSS1 & 3.74 & 0.75 & 0.007 & 2.24 & 0.72 & 0.027 \\
\hline CCDC28A & 3.39 & 1.33 & $6.92 \mathrm{E}-04$ & 2.38 & 1.33 & 0.027 \\
\hline ETNK1 & 6.47 & 1.12 & 0.010 & 5.65 & 1.25 & 0.027 \\
\hline SNAP23 & 6.44 & 1.10 & 0.050 & 6.19 & 1.23 & 0.027 \\
\hline TUBG1 & 5.00 & 0.84 & 0.016 & 5.01 & 0.81 & 0.028 \\
\hline RRS1 & 5.59 & 0.85 & 0.004 & 3.69 & 0.72 & 0.029 \\
\hline MATN2 & 5.79 & 1.39 & 8.99E-04 & 5.89 & 1.28 & 0.032 \\
\hline NCAPH & 5.88 & 0.76 & 0.007 & 3.31 & 0.69 & 0.032 \\
\hline AKAP3 & 0.90 & 1.44 & 0.033 & 1.59 & 1.41 & 0.032 \\
\hline MPV17L2 & 3.69 & 0.81 & 0.001 & 4.46 & 0.77 & 0.032 \\
\hline PTGES2 & 6.47 & 0.89 & 0.023 & 5.85 & 0.74 & 0.034 \\
\hline WDR4 & 4.54 & 0.79 & 0.005 & 2.11 & 0.76 & 0.036 \\
\hline TXNIP & 7.50 & 1.38 & $5.31 \mathrm{E}-04$ & 4.36 & 1.30 & 0.037 \\
\hline
\end{tabular}


Table 1 continued

\begin{tabular}{|c|c|c|c|c|c|c|}
\hline \multirow[t]{2}{*}{ Gene } & \multicolumn{3}{|c|}{ ERBB2-overexpressing cancer cell lines } & \multicolumn{3}{|c|}{ iPSC-derived cardiomyocytes } \\
\hline & $\log C P M$ & $\mathrm{FC}$ & $p$ value & $\log C P M$ & FC & $p$ value \\
\hline TOPЗА & 6.15 & 0.87 & 0.007 & 4.74 & 0.84 & 0.038 \\
\hline PDK4 & 1.08 & 2.20 & $1.80 \mathrm{E}-05$ & 2.77 & 1.43 & 0.039 \\
\hline BCAS3 & 4.46 & 1.21 & 0.009 & 4.42 & 1.25 & 0.039 \\
\hline$R R M 2$ & 8.39 & 0.76 & 0.014 & 5.27 & 0.77 & 0.039 \\
\hline $\mathrm{CHCHD3}$ & 6.22 & 0.87 & 0.031 & 6.56 & 0.82 & 0.039 \\
\hline MBNL2 & 6.95 & 1.12 & 0.023 & 5.89 & 1.31 & 0.040 \\
\hline RAB17 & 5.09 & 1.17 & 0.039 & 2.04 & 1.50 & 0.040 \\
\hline BIRC5 & 6.58 & 0.79 & 0.023 & 4.81 & 0.70 & 0.040 \\
\hline PGAM5 & 6.54 & 0.82 & $3.46 \mathrm{E}-04$ & 5.09 & 0.80 & 0.040 \\
\hline IDII & 7.37 & 0.82 & 0.003 & 5.76 & 0.82 & 0.043 \\
\hline FADS2 & 7.15 & 0.76 & 0.013 & 6.90 & 0.81 & 0.046 \\
\hline RNASEH $2 A$ & 5.57 & 0.85 & 0.033 & 3.52 & 0.69 & 0.046 \\
\hline NFASC & 4.95 & 1.55 & 0.005 & 0.68 & 1.58 & 0.048 \\
\hline PAKIIPI & 5.00 & 0.89 & 0.048 & 2.88 & 0.81 & 0.049 \\
\hline DHFR & 6.93 & 0.86 & 0.018 & 6.46 & 0.82 & 0.049 \\
\hline FHLI & 3.30 & 1.49 & 0.041 & 7.24 & 1.21 & 0.050 \\
\hline$P R O D H$ & 7.11 & 1.24 & 0.005 & 2.43 & 0.59 & 0.003 \\
\hline KCNQ5 & 0.32 & 0.57 & 0.019 & 4.02 & 1.54 & 0.006 \\
\hline PIM1 & 4.28 & 1.25 & 0.005 & 3.68 & 0.72 & 0.006 \\
\hline MAP6D1 & 3.06 & 1.17 & 0.038 & 2.05 & 0.70 & 0.011 \\
\hline TLLI & -0.08 & 0.64 & 0.049 & 2.36 & 1.76 & 0.013 \\
\hline DYNCILII & 5.67 & 0.89 & 0.022 & 7.96 & 1.28 & 0.015 \\
\hline MXRA5 & 6.22 & 0.83 & 0.019 & 1.33 & 1.90 & 0.015 \\
\hline RILPL2 & 3.16 & 1.27 & 0.012 & 2.11 & 0.72 & 0.023 \\
\hline RPL18A & 8.66 & 1.11 & 0.028 & 5.97 & 0.77 & 0.032 \\
\hline NAGLU & 4.69 & 1.17 & 0.023 & 3.64 & 0.76 & 0.034 \\
\hline RNF39 & 3.05 & 1.28 & 0.046 & 1.04 & 0.70 & 0.039 \\
\hline RPS18 & 9.84 & 1.11 & 0.041 & 8.29 & 0.76 & 0.040 \\
\hline ARHGAP18 & 4.99 & 1.11 & 0.040 & 0.74 & 0.67 & 0.048 \\
\hline
\end{tabular}

63/76 genes showed fold changes in the same direction. 13 genes with FC in the opposite direction between cancer cell lines and iPSC-derived cardiomyocytes are listed at the bottom of the table in italics. All genes are ordered by $\mathrm{p}$ values in cardiomyocytes

Differential gene expression analyses were performed in six cancer cell lines overexpressing ERBB2 (BT474, HCC1419, HCC1569, HCC1954, MDAMB453 and SKBR3) and in iPSC-derived cardiomyocytes following treatment with trastuzumab

iPSC induced pluripotent stem cell, $\log C P M \log 2$ counts per million, FC fold change

$\mathrm{p}=4.94 \times 10^{-4} ; \mathrm{GO}: 0008203, \mathrm{p}=3.90 \times 10^{-3}$ respectively) and ERBB2-overexpressing cells treated with trastuzumab (GO:0044281, p $=1.23 \times 10^{-10}$; GO:0008203, $\left.\mathrm{p}=1.35 \times 10^{-3}\right)($ Table 3$)$.

Trastuzumab induced ERBB2 inhibition down-regulates glucose uptake in iPSC-derived cardiomyocytes

Following the link to trastuzumab induced differential expression of genes involved in metabolism, which included up-regulation (confirmed at the level of protein, Fig. 5), of PDK4, an inhibitor of the pyruvate dehydrogenase complex and hence glycolysis, and down-regulation of multiple genes located in the mitochondria, perhaps reflecting a reduction in oxidative phosphorylation, (ALDH1L2, SLC27A3, SLC25A25, SLC25A5, SLC25A6 and UCP2, fold change and $\mathrm{p}$ values in Additional file 1: Table S1), we next examined the effect of trastuzumab on glycolysis. Following treatment with trastuzumab, we measured glucose uptake (based on measuring the amount of glucose in the media) up to $96 \mathrm{~h}$. Cardiomyocytes treated with trastuzumab showed significantly higher amounts of glucose in the media (hence lower glucose uptake) as early as $24 \mathrm{~h}$ post-treatment $(\mathrm{p}=0.001)$, and this difference remained significant up to $96 \mathrm{~h}$ post-treatment $(\mathrm{p}=0.03),($ Fig. 6) . 
Table 2 Differentially expressed genes in cardiomyocytes following ERBB2 inhibition

\begin{tabular}{|c|c|c|c|c|c|}
\hline \multirow[t]{2}{*}{ Gene } & \multirow[t]{2}{*}{$\log C P M$} & \multicolumn{2}{|c|}{$\begin{array}{l}\text { iPSC cardiomyocytes } \\
\text { treated with trastu- } \\
\text { zumab }\end{array}$} & \multicolumn{2}{|c|}{$\begin{array}{l}\text { iPSC cardiomy- } \\
\text { oytes treated } \\
\text { with lapatinib }\end{array}$} \\
\hline & & $\mathrm{FC}$ & p value & $\mathrm{FC}$ & p value \\
\hline PHLDA1 & 4.366 & 0.53 & 0.003 & 0.29 & $8.89 E-09$ \\
\hline SLC6A6 & 3.051 & 0.53 & 0.006 & 0.27 & $2.35 \mathrm{E}-08$ \\
\hline RGS4 & 1.850 & 0.66 & 0.022 & 0.41 & $1.15 \mathrm{E}-06$ \\
\hline LDLR & 5.843 & 0.66 & 0.007 & 0.48 & $1.98 \mathrm{E}-06$ \\
\hline RP11-290L1.3 & 2.017 & 0.44 & 0.004 & 0.26 & $3.09 E-06$ \\
\hline FSTL5 & 1.461 & 2.26 & $2.25576 \mathrm{E}-05$ & 2.23 & $2.93 \mathrm{E}-05$ \\
\hline EGR1 & 3.271 & 0.40 & $6.21035 \mathrm{E}-05$ & 0.39 & $4.71 \mathrm{E}-05$ \\
\hline KRT6A & -1.435 & 0.00 & $1.51 \mathrm{E}-04$ & 0.00 & $1.42 \mathrm{E}-04$ \\
\hline STK32A & 1.068 & 1.97 & $6.48 \mathrm{E}-04$ & 2.08 & $2.05 \mathrm{E}-04$ \\
\hline PRRT4 & 2.336 & 1.72 & $2.62 \mathrm{E}-04$ & 1.68 & $4.71 \mathrm{E}-04$ \\
\hline FAM71F2 & 0.724 & 1.91 & 0.007 & 2.22 & 0.001 \\
\hline ZNF483 & 1.654 & 1.76 & 0.018 & 2.22 & 0.001 \\
\hline ACRC & 0.475 & 1.65 & 0.025 & 2.09 & 0.001 \\
\hline RP11-285F7.2 & 0.797 & 1.66 & 0.020 & 2.03 & 0.001 \\
\hline LINC00842 & 3.506 & 1.64 & 0.001 & 1.61 & 0.002 \\
\hline RP3-434O14.8 & 0.954 & 2.14 & 0.001 & 1.97 & 0.002 \\
\hline NFASC & 0.677 & 1.58 & 0.048 & 1.99 & 0.002 \\
\hline PMCH & 0.823 & 0.64 & 0.047 & 0.51 & 0.003 \\
\hline CAV3 & 0.797 & 1.58 & 0.027 & 1.81 & 0.004 \\
\hline AL132989.1 & 0.577 & 2.04 & 0.012 & 2.18 & 0.006 \\
\hline SDC1 & 1.833 & 0.62 & 0.013 & 0.60 & 0.007 \\
\hline SLC28A1 & 1.089 & 1.96 & 0.028 & 2.25 & 0.008 \\
\hline KIAA1107 & 2.568 & 1.54 & 0.028 & 1.68 & 0.008 \\
\hline PLK3 & 0.683 & 0.55 & 0.006 & 0.56 & 0.009 \\
\hline SLC7A7 & 1.628 & 2.00 & $1.39564 \mathrm{E}-05$ & 1.51 & 0.011 \\
\hline GRM8 & 0.678 & 1.92 & 0.011 & 1.89 & 0.012 \\
\hline NPY4R & 0.487 & 1.85 & 0.032 & 2.06 & 0.012 \\
\hline FAM110A & 1.255 & 0.64 & 0.011 & 0.66 & 0.016 \\
\hline GFAP & 1.856 & 0.62 & 0.006 & 0.66 & 0.017 \\
\hline APBB1IP & 0.323 & 2.46 & 0.003 & 2.06 & 0.019 \\
\hline IL31RA & 0.956 & 3.85 & $1.56156 \mathrm{E}-06$ & 1.94 & 0.020 \\
\hline RPP25 & 2.028 & 0.65 & 0.045 & 0.61 & 0.020 \\
\hline AC007036.5 & 2.769 & 1.64 & 0.023 & 1.66 & 0.020 \\
\hline LINC00327 & 0.750 & 1.59 & 0.009 & 1.51 & 0.021 \\
\hline PKN3 & 2.451 & 0.65 & 0.024 & 0.66 & 0.024 \\
\hline MTFP1 & 2.980 & 0.64 & 0.037 & 0.62 & 0.026 \\
\hline PROM1 & 1.535 & 1.69 & 0.010 & 1.55 & 0.031 \\
\hline ATF4P3 & 1.473 & 0.58 & 0.007 & 0.66 & 0.038 \\
\hline
\end{tabular}

Overlap of trastuzumab and lapatinib differentially expressed genes in cardiomyocytes, fold change $>1.5, \mathrm{p}<0.05$

iPSC induced pluripotent stem cell, $F C$ fold change

Trastuzumab induced ERBB2 inhibition did not alter lactate production in iPSC-derived cardiomyocytes

Pyruvate can be converted to either lactate in the glycolytic pathway, or to acetyl co-enzyme A via the pyruvate dehydrogenase complex, linking glycolysis to the tricarboxylic (TCA) cycle and fatty acid synthesis. Our differential expression data showed up-regulation of $P D K 4$, an inhibitor of the pyruvate dehydrogenase complex, suggesting that trastuzumab could increase lactate production. We measured lactate production in cardiomyocyte media following $48 \mathrm{~h}$ treatment with trastuzumab. However, we did not observe any change in lactate production, despite significantly lower glucose uptake (Fig. 7).

\section{Discussion}

Current standard of care requires patients to receive trastuzumab for 12 months during which time they are monitored by echocardiography. Those patients experiencing significant declines in LVEF are treated with standard heart failure medications such as beta blockers or ACE inhibitors, and if LVEF does not recover, trastuzumab may be withheld. We hypothesized that identifying early changes in gene expression mediated by trastuzumab could potentially identify novel therapeutic targets for prevention of cardiac side-effects or potential biomarkers of drug-induced cardiotoxicity. We used commercially available, human iPSC-derived cardiomyocytes from a "healthy" female individual, treated with clinically relevant ERBB2 targeted therapies, trastuzumab and lapatinib to identify early therapy induced changes. We identified two groups of genes that may be relevant in the management of cardiotoxicity.

Firstly, the small group of significantly differentially expressed genes in iPSC-derived cardiomyocytes treated with trastuzumab and lapatinib, related to cardiac dysfunction and ischemic injury. EGR1 and PHLDA1, both down-regulated in our experiments, are significantly upregulated in ischemic preconditioning [17], suggesting perhaps that prevention of this change in gene expression could be protective against ERBB2 therapy related cardiotoxicity. Absence of regulator of G-protein signaling 4 (RGS4) predisposes to atrial fibrillation and is associated with abnormal calcium handling [33] and activation of RGS4 mediates the cardioprotective effects of natriuretic peptides in the heart [34], of which natriuretic peptide A, NPPA, was also significantly down-regulated by trastuzumab and lapatinib. Solute carrier family 6 , member 6 (SLC6A6), is a transporter of taurine, an endogenous sulfur-containing beta-amino acid, associated with calcium handling, protection against ischemia-reperfusion injury, heart failure ischemic heart disease, and diabetic cardiomyopathy [35]. Slc6a6 knock out mouse models demonstrate a phenotype of dilated cardiomyopathy with cardiac atrophy [36], lower fasting blood glucose, acceleration of glycolysis in skeletal muscle and susceptibility to development of obesity when placed on a high fat diet [37]. Taken together, our findings of trastuzumab 

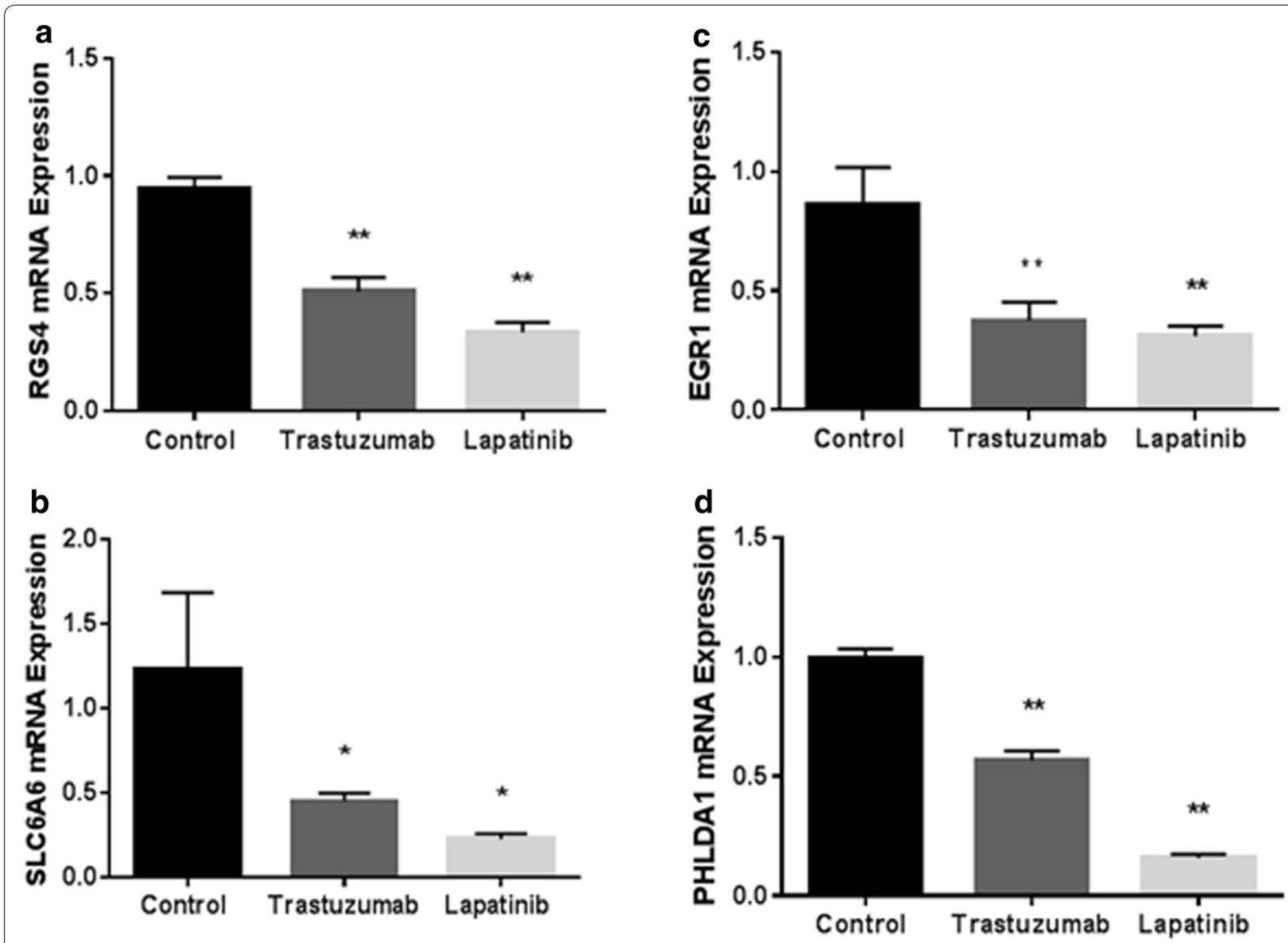

Fig. 4 qPCR validation of differential expression of RGS4, EGR1, SLC6A6 and PHLDA1 by trastuzumab and lapatinib in iPSC-derived cardiomyocytes. Standard deviation (SD) calculated from three replicates. Down-regulation of: a RGS4, b SLC6A6, c EGR1 and d PHLDA1 by trastuzumab and lapatinib was confirmed by $\mathrm{qPCR}$. Student's T-test, unequal values, $\mathrm{p}<0.05^{*} ; \mathrm{p}<0.01^{* *}$

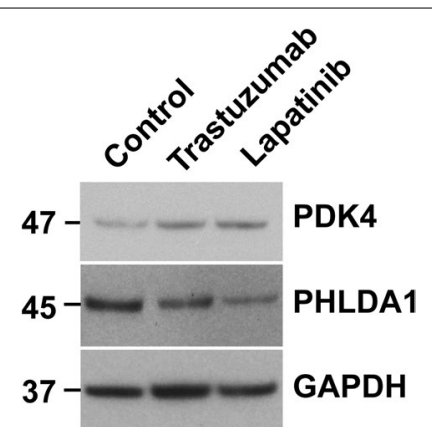

Fig. 5 Trastuzumab and lapatinib induced down-regulation of PHLDA1 protein expression and up-regulation of PDK4 protein expression. Western blot of $15 \mu \mathrm{g}$ of total cell lysate of iPSC-derived cardiomyocytes stained for PHLDA1 and PDK4

induced down-regulation of SLC6A6 in human iPSCderived cardiomyocytes, and the reported phenotypes of dilated cardiomyopathy and altered metabolism in Slc6a6 knock-out mice provide a potential mechanism towards trastuzumab related cardiotoxicity.

The second group of trastuzumab regulated genes in our iPSC-derived cardiomyocyte model involved metabolism. Enrichment analyses identified gene ontology categories: small molecule metabolism, cholesterol and sterol metabolism and cholesterol and sterol biosynthesis, and expression of the majority of genes in these categories was down-regulated across iPSC-derived cardiomyocytes treated with trastuzumab and lapatinib and also in cancer cell lines overexpressing ERBB2. In the case of iPSC-derived cardiomyocytes treated with trastuzumab, specifically, only metabolic gene ontology categories were significantly enriched. This is in contrast to ERBB2-overexpressing cancer cell lines treated with trastuzumab, in which the most significantly enriched categories related to cell cycle. We note at this point, a similar pattern in trastuzumab-induced down-regulation of ERBB2 protein levels between cancer cells and cardiomyocytes. In our 
Table 3 Gene ontology enrichment analysis

\begin{tabular}{|c|c|c|c|c|c|}
\hline & $\begin{array}{l}\text { Small molecule } \\
\text { metabolic process } \\
(\mathrm{GO} 0044281)\end{array}$ & $\begin{array}{l}\text { Cholesterol } \\
\text { metabolic process } \\
\text { (GO:0008203) }\end{array}$ & $\begin{array}{l}\text { Sterol metabolic pro- } \\
\text { cess (GO:0016125) }\end{array}$ & $\begin{array}{l}\text { Cholesterol bio- } \\
\text { synthetic process } \\
\text { (GO:0006695) }\end{array}$ & $\begin{array}{l}\text { Sterol biosynthetic } \\
\text { process (GO:0016126) }\end{array}$ \\
\hline \multicolumn{6}{|c|}{ iPSC cardiomycytes treated with trastuzumab } \\
\hline $\begin{array}{l}\text { Genes uploaded to } \\
\text { enrichment analysis }\end{array}$ & $428 / 517$ & $428 / 517$ & $428 / 517$ & $428 / 517$ & $428 / 517$ \\
\hline $\begin{array}{l}\text { Uploaded genes in } \\
\text { category }\end{array}$ & 98 & 12 & NS & 8 & 8 \\
\hline $\begin{array}{l}\text { Expected genes in } \\
\text { category }\end{array}$ & 45.92 & 2.24 & & 0.78 & 0.88 \\
\hline $\begin{array}{l}\text { Category fold enrich- } \\
\text { ment }\end{array}$ & 2.13 & $>5$ & & $>5$ & $>5$ \\
\hline p value (adjusted) & $3.22 \mathrm{E}-09$ & 0.030 & & 0.013 & 0.031 \\
\hline \multicolumn{6}{|c|}{ iPSC cardiomycoytes treated with lapatinib } \\
\hline $\begin{array}{l}\text { Genes uploaded to } \\
\text { enrichment analysis }\end{array}$ & 1077/1358 & $1077 / 1358$ & $1077 / 1358$ & $1077 / 1358$ & $1077 / 1358$ \\
\hline $\begin{array}{l}\text { Uploaded genes in } \\
\text { category }\end{array}$ & 173 & 21 & 21 & 12 & 12 \\
\hline $\begin{array}{l}\text { Expected genes in } \\
\text { category }\end{array}$ & 115.54 & 5.64 & 6.31 & 1.97 & 2.22 \\
\hline $\begin{array}{l}\text { Category fold enrich- } \\
\text { ment }\end{array}$ & 1.5 & 3.72 & 3.33 & $>5$ & $>5$ \\
\hline p value (adjusted) & $4.94 \mathrm{E}-04$ & 0.004 & 0.022 & 0.009 & 0.030 \\
\hline \multicolumn{6}{|c|}{ ERBB2-overexpressing cancer cell lines treated with trastuzumab } \\
\hline $\begin{array}{l}\text { Genes uploaded to } \\
\text { enrichment analysis }\end{array}$ & 2097/2272 & $2097 / 2272$ & $2097 / 2272$ & $2097 / 2272$ & $2097 / 2272$ \\
\hline $\begin{array}{l}\text { Uploaded genes in } \\
\text { category }\end{array}$ & 340 & 32 & 32 & 22 & 22 \\
\hline $\begin{array}{l}\text { Expected genes in } \\
\text { category }\end{array}$ & 224.97 & 10.98 & 12.29 & 3.83 & 4.33 \\
\hline $\begin{array}{l}\text { Category fold enrich- } \\
\text { ment }\end{array}$ & 1.51 & 2.91 & 2.6 & $>5$ & $>5$ \\
\hline p value (adjusted) & $1.23 \mathrm{E}-10$ & 0.001 & 0.014 & $1.12 \mathrm{E}-06$ & $1.06 \mathrm{E}-05$ \\
\hline
\end{tabular}

Differentially expressed genes following treatment with trastuzumab or lapatinib were assessed for enrichment in gene ontology categories of biological process. 517 genes were significantly differentially expressed in iPSC-derived cardiomyocytes following treatment with trastuzumab. 428/517 genes were recognized within the Gene Ontology (GO) Consortium reference dataset of 20,814 genes and analyzed for enrichment. Similarly, of 1358 differentially expressed genes following treatment of iPSC-derived cardiomyocytes with lapatinib, 1077 were recognized in the GO reference set and analyzed for enrichment. Of 2272 differentially expressed genes following treatment with trastuzumab in ERBB2-overexpressing cancer cell lines, 2097 were recognized in the GO reference set and analyzed for enrichment. Enrichment analyses showed 1.5- >5-fold enrichment of genes in cholesterol processing pathways relative to expected, based on the annotated reference set of 20,814 genes

data, and that of others, ERBB2 was down-regulated by trastuzumab in cardiomyocytes [38] but not in ERBB2 overexpressing cancer cell lines [39]. This is not surprising given the different mechanisms of inhibition of ERBB2 signaling and trafficking between cancer cells and cardiomyocytes [40, 41], in which treatment results in reduced proliferation and induction of apoptosis in cancer cell lines $[42,43]$ and reduced contractility without apoptosis in cardiomyocytes, (Additional file 9: Figure S3) $[12,44]$.

Regards enrichment of differential expression of metabolism related genes, the largest metabolic category, was small molecule metabolism ( $\mathrm{N}=98$ genes), which included the taurine transporter, SLC6A6, key enzymes in glucose metabolism (PDK4 and GLA) and mitochondrial transporters (SLC27A3, SLC25A25, SLC25A5, SLC25A6). Due to the high energy demand of the heart, cardiac metabolism is highly flexible. In the 'normal/healthy' heart, mitochondria are primarily fueled by the metabolites of fatty acids and carbohydrates, but under chronic pathological conditions, the heart has the capacity to remodel metabolic pathways, and subsequently, myocardial energetics and contractile function [45], although these data relate mostly to reprogramming in response 


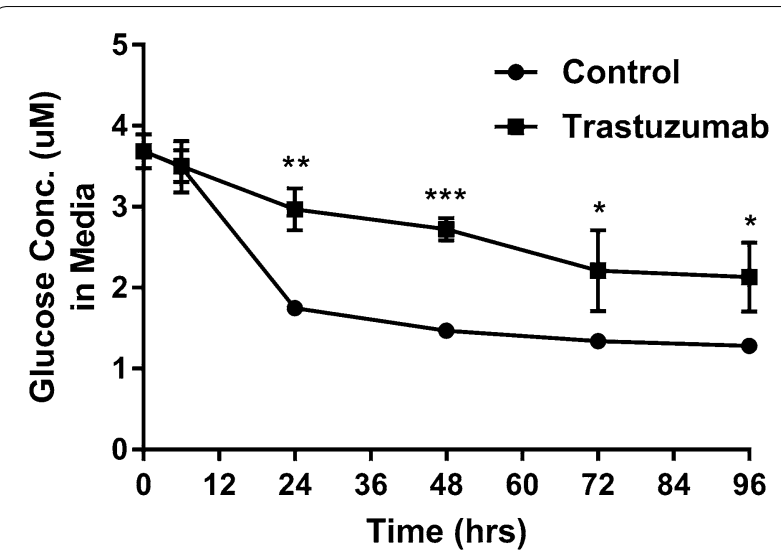

Fig. 6 Down-regulation of glucose levels in the media of iPSCderived cardiomyocytes following treatment with trastuzumab. Standard deviation (SD) calculated from three replicates. Time course of glucose concentration in the media of iPSC-derived cardiomyocytes treated with trastuzumab versus untreated (control). ${ }^{*} p=0.04$ (72 h), $p=0.026(96 h) ;{ }^{* *} p=0.001(24 h),{ }^{* * *} p<0.0002(48 h)$

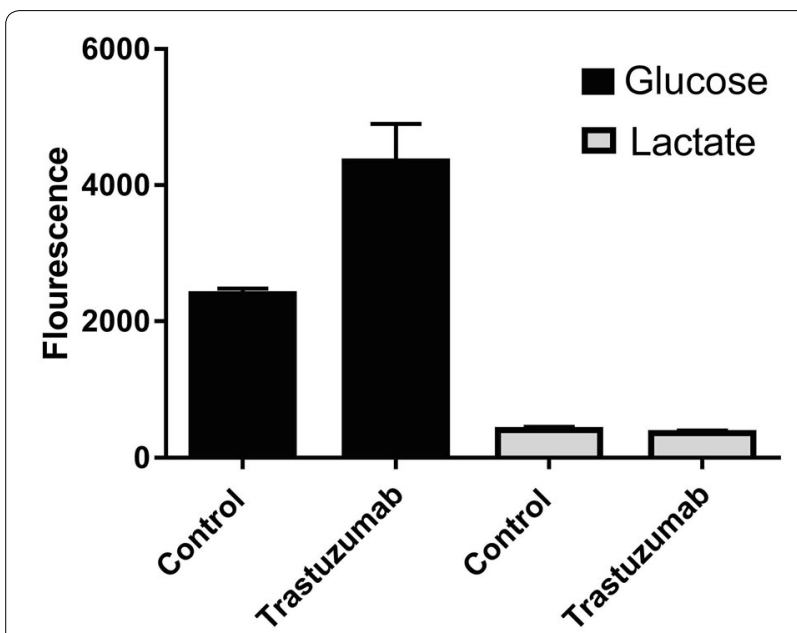

Fig. 7 Glucose and lactate levels in the media of iPSC-derived cardiomyocytes following $48 \mathrm{~h}$ treatment with trastuzumab. Standard deviation (SD) calculated from three replicates. Glucose levels were significantly higher in the media of iPSC-derived cardiomyocytes treated with trastuzumab relative to untreated cells, ${ }^{*} p=0.004$. Levels of lactate were not significantly different between iPSCderived cardiomyocytes treated with trastuzumab and untreated cell, $p=0.329$

to pathological hypertrophy, characterized by increased reliance on glucose metabolism and decreased fatty acid oxidation. The effect of trastuzumab, on glucose uptake in iPSC-derived cardiomyocytes suggests a different metabolic change to that observed in cardiac hypertrophy. We observed significantly more glucose in the media of iPSC-derived cardiomyocytes treated with trastuzumab within $24 \mathrm{~h}$ and constantly up to $96 \mathrm{~h}$, indicative of a lower uptake of glucose as a result of trastuzumab, with negligible change in lactate. These observations are in line with studies of "lipid status" responsiveness, whereby up-regulation of PDK4, facilitates fatty acid oxidation by "sparing" pyruvate for oxaloacetate formation [46, 47]. In heart and skeletal muscle, increased anaplerotic entry of pyruvate into the TCA cycle as oxaloacetate facilitates entry of acetyl co-A derived from fatty acid $\beta$-oxidation into the TCA cycle through increased citrate formation, which in turn, acts as a sensor of fatty acid abundance and suppresses glucose uptake [46].

Observations of trastuzumab induced changes in metabolism are clinically relevant in light of potential metabolic therapies for heart failure. For example, dichloracetate (DCA), a drug shown to improve cardiac function in right ventricular hypertrophy and failure [48, 49], increases pyruvate dehydrogenase activity by inhibiting PDK, and perhaps could potentially reverse the effects of trastuzumab. The efficacy of DCA treatment has also been demonstrated in functional recovery during reperfusion in multiple animal models [50-53]. Lewandowski and White [52] demonstrated that counteracting depressed pyruvate oxidation enhanced contractile recovery in post-ischemic rabbit hearts. Of note, two of the most consistently down-regulated genes following ERBB2 inhibition, were EGR1 and PHLDA1, which have also been shown to be up-regulated in models of ischemic preconditioning [17].

In summary our transcriptome based approach of trastuzumab induced changes in iPSC-derived cardiomyocytes identified significant down-regulation of expression of genes associated with ischemic preconditioning and cardiac dysfunction, and more significantly with genes involved in metabolism. The main caveats of the study are the reliance on an in vitro model of iPSC-derived cardiomyocytes which may not reflect fully mature differentiated human cardiomyocytes and does not address potential immune response, and lack of functional data. However, our reported changes of trastuzumab mediated differential gene expression in cardiomyocytes were validated with additional ERBB2 targeted compounds and we also observed considerable overlap in ERBB2-overexpressing cancer cell lines which we interpret as strong evidence that ERBB2 inhibition is responsible for our reported changes in gene expression. We acknowledge, it is not proven that these specific genes functionally contribute to dysregulation of glycolysis in iPSC-derived cardiomyocytes, but we note that knock out of slc6a6, one of the most consistently, differentially expressed genes in our human study, resulted in a phenotype of accelerated glycolysis in skeletal muscle in a mouse model [36]. 


\section{Additional files}

Additional file 1: Table S1. RNASeq differential expression analysis of iPSC derived cardiomyocytes following $48 \mathrm{~h}$ treatment with trastuzumab.

Additional file 2: Figure S1. Overlap of genes expressed above background (A) and differentially expressed genes (B) in iPSC-derived cardiomyocytes and ERBB2-overexpressing cancer cells.

Additional file 3: Table S2. RNASeq differential expression analysis of iPSC derived cardiomyocytes following $48 \mathrm{~h}$ treatment with lapatinib.

Additional file 4: Figure S2. Differential expression in iPSC-derived cardiomyocytes following treatment withadditional tyrosine kinase inhibitors of ERBB2 (afatinib, lapatinib, neratinib, poziotinib). Standard deviation (SD) calculated from three replicates. (A) RGS4, (B) SLC6A6, (C) EGR1 and (D) PHLDA1. Student's T-test, unequal values, $p<0.05^{*} ; p<0.01^{* *}$

Additional file 5: Table S3. Gene ontology enrichment analysis of trastuzumab induced differentially expressed genes in ERBB2 overexpressing cancer cell lines.

Additional file 6: Table S4. Gene ontology enrichment analysis of lapatinib induced differentially expressed genes in IPSC dervied cardiomyocytes.

Additional file 7: Table S5. Gene ontology enrichment analysis of trastuzumab induced differentially expressed genes in iPSC dervied cardiomyocytes.

Additional file 8: Table S6. Differentially expressed genes in Gene ontology categories of cholesterol and sterol metabolism and biosynthesis.

Additional file 9: Figure S3. Treatment of iPSC-derived cardiomyocytes with trastuzumab did not result in apoptosis. Standard error (SD) calculated from four replicate reactions.

\section{Authors' contributions}

NN designed and directed the study and drafted the manuscript. DJS carried out differential expression transcriptome analysis. BMN, BCA and JMK carried out laboratory assays. EAT and EAP provided input to study design, reviewed and edited the manuscript. All authors read and approved the final manuscript.

\section{Author details}

${ }^{1}$ Department of Cancer Biology, Mayo Clinic, Jacksonville, FL, USA. ${ }^{2}$ Department of Health Sciences Research, Mayo Clinic, Jacksonville, FL, USA. ${ }^{3}$ Department of Hematology Oncology, Mayo Clinic, Jacksonville, FL, USA.

\section{Competing interests}

The authors declare that they have no competing interests.

\section{Funding}

This study was funded by Mayo Clinic Transplant and Regenerative Medicine Focused Research Group, The MacKenzie Foundation, The Gerstner Award and The 26.2 with Donna Foundation.

Received: 7 November 2016 Accepted: 21 December 2016 Published online: 18 January 2017

\section{References}

1. Slamon DJ, Leyland-Jones B, Shak S, Fuchs H, Paton V, Bajamonde A et al (2001) Use of chemotherapy plus a monoclonal antibody against HER2 for metastatic breast cancer that overexpresses HER2. New Engl I Med. 344(11):783-792

2. Fried G, Regev T, Moskovitz M (2013) Trastuzumab-related cardiac events in the treatment of early breast cancer. Breast Cancer Res Treat 142(1):1-7

3. Montserrat M, Leveque D, Barthelemy P, Bergerat JP (2012) Duration of adjuvant trastuzumab treatment in routine practice. Anticancer Res 32(10):4585-4588
4. Murray LJ, Ramakrishnan S, O'Toole L, Manifold IH, Purohit OP, Coleman RE (2010) Adjuvant trastuzumab in routine clinical practice and the impact of cardiac monitoring guidelines on treatment delivery. Breast. 19(5):339-344

5. Piccart-Gebhart MJ, Procter M, Leyland-Jones B, Goldhirsch A, Untch M, Smith I et al (2005) Trastuzumab after adjuvant chemotherapy in HER2positive breast cancer. N Engl J Med 353(16):1659-1672

6. Piotrowski G, Gawor R, Stasiak A, Gawor Z, Potemski P, Banach M (2012) Cardiac complications associated with trastuzumab in the setting of adjuvant chemotherapy for breast cancer overexpressing human epidermal growth factor receptor type 2-a prospective study. Arch Med Sci. 8(2):227-235

7. Romond EH, Perez EA, Bryant J, Suman VJ, Geyer CE Jr, Davidson NE et al (2005) Trastuzumab plus adjuvant chemotherapy for operable HER2positive breast cancer. N Engl J Med 353(16):1673-1684

8. Spielmann M, Roche H, Delozier T, Canon JL, Romieu G, Bourgeois H et al (2009) Trastuzumab for patients with axillary-node-positive breast cancer: results of the FNCLCC-PACS 04 trial. J Clin Oncol 27(36):6129-6134

9. Tarantini L, Cioffi G, Gori S, Tuccia F, Boccardi L, Bovelli D et al (2012) Trastuzumab adjuvant chemotherapy and cardiotoxicity in real-world women with breast cancer. J Card Fail. 18(2):113-119

10. Webster RM, Abraham J, Palaniappan N, Caley A, Jasani B, Barrett-Lee $P(2012)$ Exploring the use and impact of adjuvant trastuzumab for HER2-positive breast cancer patients in a large UK cancer network. Do the results of international clinical trials translate into a similar benefit for patients in South East Wales? Br J Cancer 106(1):32-38

11. Wang SY, Long JB, Hurria A, Owusu C, Steingart RM, Gross CP et al (2014) Cardiovascular events, early discontinuation of trastuzumab, and their impact on survival. Breast Cancer Res Treat 146(2):411-419

12. Plana JC, Galderisi M, Barac A, Ewer MS, Ky B, Scherrer-Crosbie M et al (2014) Expert consensus for multimodality imaging evaluation of adult patients during and after cancer therapy: a report from the American Society of Echocardiography and the European Association of Cardiovascular Imaging. Eur Heart J Cardiovasc Imaging. 15(10):1063-1093

13. Plana JC, Galderisi M, Barac A, Ewer MS, Ky B, Scherrer-Crosbie M et al (2014) Expert consensus for multimodality imaging evaluation of adult patients during and after cancer therapy: a report from the American Society of Echocardiography and the European Association of Cardiovascular Imaging. J Am Soc Echocardiogr 27(9):911-939

14. Crone SA, Zhao YY, Fan L, Gu Y, Minamisawa S, Liu Y et al (2002) ErbB2 is essential in the prevention of dilated cardiomyopathy. Nat Med 8(5):459-465

15. Negro A, Brar BK, Lee KF (2004) Essential roles of Her2/erbB2 in cardiac development and function. Recent Prog Horm Res 59:1-12

16. ElZarrad MK, Mukhopadhyay P, Mohan N, Hao E, Dokmanovic M, Hirsch DS et al (2013) Trastuzumab alters the expression of genes essential for cardiac function and induces ultrastructural changes of cardiomyocytes in mice. PLOS ONE 8(11):e79543

17. Liu L, Zhu J, Glass PS, Brink PR, Rampil IJ, Rebecchi MJ (2009) Ageassociated changes in cardiac gene expression after preconditioning. Anesthesiology 111(5):1052-1064

18. Reischauer S, Arnaout R, Ramadass R, Stainier D (2014) Actin binding GFP allows 4D in vivo imaging of myofilament dynamics in the zebrafish heart and the identification of Erbb2 signaling as a remodeling factor of myofibril architecture. Circ Res 115(10):845-856

19. Reischauer S, Levesque MP, Nusslein-Volhard C, Sonawane M (2009) Lgl2 executes its function as a tumor suppressor by regulating ErbB signaling in the zebrafish epidermis. PLoS Genet 5(11):e1000720

20. Aggarwal P, Turner A, Matter A, Kattman SJ, Stoddard A, Lorier R et al (2014) RNA expression profiling of human iPSC-derived cardiomyocytes in a cardiac hypertrophy model. PLoS ONE 9(9):e108051

21. Heidecker B, Lamirault G, Kasper EK, Wittstein IS, Champion HC, Breton E et al (2010) The gene expression profile of patients with new-onset heart failure reveals important gender-specific differences. Eur Heart J 31(10):1188-1196

22. Kittleson MM, Hare JM (2005) Molecular signature analysis: the potential of gene-expression analysis in cardiomyopathy. Future Cardiol. 1(6):793-808

23. Kittleson MM, Hare JM (2005) Molecular signature analysis: using the myocardial transcriptome as a biomarker in cardiovascular disease. Trends Cardiovasc Med 15(4):130-138 
24. Kittleson MM, Minhas KM, Irizarry RA, Ye SQ, Edness G, Breton E et al (2005) Gene expression analysis of ischemic and nonischemic cardiomyopathy: shared and distinct genes in the development of heart failure. Physiol Genom 21(3):299-307

25. Kittleson MM, Ye SQ, Irizarry RA, Minhas KM, Edness G, Conte JV et a (2004) Identification of a gene expression profile that differentiates between ischemic and nonischemic cardiomyopathy. Circulation 110(22):3444-3451

26. Treish I, Schwartz R, Lindley C (2000) Pharmacology and therapeutic use of trastuzumab in breast cancer. Am J Health-Syst Ph. 57(22):2063-2076

27. Zhu S, Cawley SM, Bloch KD, Huang PL (2013) Trastuzumab and lapatinib differ in effects on calcium cycling and HER2 expression in human embryonic stem cell-derived cardiomyocytes. Cardiovasc Sys 1:10

28. Kalari KR, Nair AA, Bhavsar JD, O'Brien DR, Davila Jl, Bockol MA et al (2014) MAP-RSeq: mayo analysis pipeline for RNA sequencing. BMC Bioinform 15:224

29. Radonic A, Thulke S, Mackay IM, Landt O, Siegert W, Nitsche A (2004) Guideline to reference gene selection for quantitative real-time PCR. Biochem Biophys Res Commun 313(4):856-862

30. Livak KJ, Schmittgen TD (2001) Analysis of relative gene expression data using real-time quantitative PCR and the 2(T)(-Delta Delta C) method. Methods 25(4):402-408

31. Gene Ontology Consortium (2015) Gene Ontology Consortium: going forward. Nucleic Acids Res 43((Database issue)):1049-1056

32. Ashburner M, Ball CA, Blake JA, Botstein D, Butler H, Cherry JM et al (2000) Gene ontology: tool for the unification of biology. The Gene Ontology Consortium. Nat Genet 25(1):25-29

33. Opel A, Nobles M, Montaigne D, Finlay M, Anderson N, Breckenridge $R$ et al (2015) Absence of the regulator of G-protein signalling, RGS4, predisposes to atrial fibrillation and is associated with abnormal calcium handling. J Biol Chem 290(31):19233-19244

34. Tokudome T, Kishimoto I, Horio T, Arai Y, Schwenke DO, Hino J et al (2008) Regulator of $\mathrm{G}$-protein signaling subtype 4 mediates antihypertrophic effect of locally secreted natriuretic peptides in the heart. Circulation 117(18):2329-2339

35. Xu YJ, Arneja AS, Tappia PS, Dhalla NS (2008) The potential health benefits of taurine in cardiovascular disease. Exp Clin Cardiol. 13(2):57-65

36. Ito T, Kimura Y, Uozumi Y, Takai M, Muraoka S, Matsuda T et al (2008) Taurine depletion caused by knocking out the taurine transporter gene leads to cardiomyopathy with cardiac atrophy. J Mol Cell Cardiol 44(5):927-937

37. Ito T, Yoshikawa N, Ito H, Schaffer SW (2015) Impact of taurine depletion on glucose control and insulin secretion in mice. J Pharmacol Sci. 129(1):59-64

38. Perry MC, Dufour CR, Eichner LJ, Tsang DW, Deblois G, Muller WJ et al (2014) ERBB2 deficiency alters an E2F-1-dependent adaptive stress response and leads to cardiac dysfunction. Mol Cell Biol 34(23):4232-4243

39. Austin CD, De Maziere AM, Pisacane PI, van Dijk SM, Eigenbrot C, Sliwkowski MX et al (2004) Endocytosis and sorting of ErbB2 and the site of action of cancer therapeutics trastuzumab and geldanamycin. Mol Biol Cell 15(12):5268-5282
40. De Keulenaer GW, Doggen K, Lemmens K (2010) The vulnerability of the heart as a pluricellular paracrine organ: lessons from unexpected triggers of heart failure in targeted ErbB2 anticancer therapy. Circ Res 106(1):35-46

41. Vermeulen Z, Segers VF, De Keulenaer GW (2016) ErbB2 signaling at the crossing between heart failure and cancer. Basic Res Cardiol 111(6):60

42. Junttila TT, Akita RW, Parsons K, Fields C, Lewis Phillips GD, Friedman LS et al (2009) Ligand-independent HER2/HER3/PI3K complex is disrupted by trastuzumab and is effectively inhibited by the PI3K inhibitor GDC0941. Cancer Cell 15(5):429-440

43. Donovan N, Crown JP, Clynes M (2006) Dual targeting of EGFR and HER-2 in breast cancer cell lines. J Clin Oncol 24(18_suppl):13132

44. Barth AS, Zhang Y, Li T, Smith RR, Chimenti I, Terrovitis I et al (2012) Functional impairment of human resident cardiac stem cells by the cardiotoxic antineoplastic agent trastuzumab. Stem Cells Transl Med. 1(4):289-297

45. Kolwicz SC Jr, Purohit S, Tian R (2013) Cardiac metabolism and its interactions with contraction, growth, and survival of cardiomyocytes. Circ Res 113(5):603-616

46. Sugden MC, Bulmer K, Holness MJ (2001) Fuel-sensing mechanisms integrating lipid and carbohydrate utilization. Biochem Soc Trans 29(Pt 2):272-278

47. Sugden MC, Holness MJ (2003) Recent advances in mechanisms regulating glucose oxidation at the level of the pyruvate dehydrogenase complex by PDKs. Am J Physiol Endocrinol Metab. 284(5):E855-E862

48. Piao L, Marsboom G, Archer SL (2010) Mitochondrial metabolic adaptation in right ventricular hypertrophy and failure. J Mol Med (Berl). 88(10):1011-1020

49. Piao L, Fang YH, Cadete VJ, Wietholt C, Urboniene D, Toth PT et al (2010) The inhibition of pyruvate dehydrogenase kinase improves impaired cardiac function and electrical remodeling in two models of right ventricular hypertrophy: resuscitating the hibernating right ventricle. J Mol Med (Berl). 88(1):47-60

50. Churchill EN, Murriel CL, Chen CH, Mochly-Rosen D, Szweda LI (2005) Reperfusion-induced translocation of deltaPKC to cardiac mitochondria prevents pyruvate dehydrogenase reactivation. Circ Res 97(1):78-85

51. Kudej RK, White LT, Kudej AB, Vatner SF, Lewandowski ED (2002) Brief increase in carbohydrate oxidation after reperfusion reverses myocardial stunning in conscious pigs. Circulation 106(22):2836-2841

52. Lewandowski ED, White LT (1995) Pyruvate dehydrogenase influences postischemic heart function. Circulation 91(7):2071-2079

53. McVeigh JJ, Lopaschuk GD (1990) Dichloroacetate stimulation of glucose oxidation improves recovery of ischemic rat hearts. Am J Physiol 259(4 Pt 2):H1079-H1085

\section{Submit your manuscript to a SpringerOpen ${ }^{\circ}$ journal and benefit from:}

- Convenient online submission

- Rigorous peer review

- Immediate publication on acceptance

- Open access: articles freely available online

- High visibility within the field

- Retaining the copyright to your article

Submit your next manuscript at $\mathbf{s p r i n g e r o p e n . c o m ~}$ 